\title{
Endovascular transarterial embolization of cerebral arteriovenous malformation with ethylene-vinyl alcohol copolymer
}

\author{
LeE A. Tan, M.D., Andrew K. Johnson, M.D., Kiffon M. Keigher, APN, \\ Roham Moftakhar, M.D., and Demetrius K. Lopes, M.D. \\ Department of Neurosurgery, Rush University Medical Center, Chicago, Illinois
}

\begin{abstract}
Cerebral arteriovenous malformations (AVMs) have an estimated 2-4\% annual risk of hemorrhage. Treatment options for AVMs include microsurgical resection, stereotactic radiosurgery, and endovascular embolization. As endovascular technology and techniques continue to advance and mature, endovascular embolization is becoming an increasingly vital component of AVM treatment not only as a presurgical treatment to reduce microsurgical risks, but also as a stand-alone curative method in some cases. This case illustrates the successful and curative transarterial embolization of a right frontal AVM in a 17-year-old boy with ethylene-vinyl alcohol copolymer (Onyx).

The video can be found here: http://youtu.be/L4hE1MvCZCY.

(http://thejns.org/doi/abs/10.3171/2014.V2.FOCUS13577)
\end{abstract}

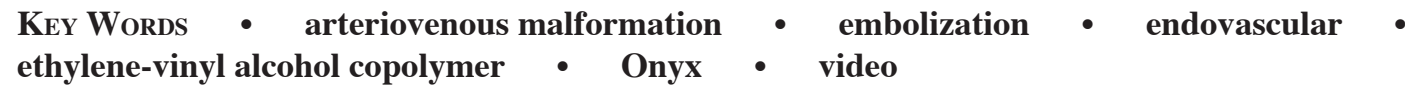

Manuscript submitted April 30, 2014.

Accepted May 21, 2014.

Please include this information when citing this paper: DOI: 10.3171/2014.V2.FOCUS13577.

Address correspondence to: Dr. Lee A. Tan, Department of Neurosurgery, Rush University Medical Center, 1725 W. Harrison St. Suite 855, Chicago, Illinois 60612. Email: lee_tan@rush.edu. 